Revista Água Viva

\title{
O ÁLBUM ENCANTADO, A RAINHA BRANCA ESPARTILHADA E A SACOLA - ELEMENTOS GÓTICOS NO CONTO DE FORMAÇÃO O ESPARTILHO DE LYGIA FAGUNDES TELLES
}

\author{
THE ENCHANTED ALBUM, WHITE QUEEN SPARKLED AND TOTE BAG - \\ GOTHIC ELEMENTS IN THE TRAINING TALE O ESPARTILHO BY LYGIA \\ FAGUNDES TELLES
}

Adriana Mattoso Rodrigues ${ }^{1}$

DOI: 10.26512/aguaviva.v3i1.12187

Recebido em: 15 abr. 2018

Aceito em: 21 jun. 2018

RESUMO: O presente artigo faz uma leitura dos elementos góticos do conto $O$ Espartilho de Lygia Fagundes Telles e o significado desses elementos na formação da protagonista. Os elementos serão analisados somente em ordem de importância na narrativa. Dentro do artigo ainda se considera a categoria "conto de formação feminino" que enseja a abordagem de vários elementos do Bildungsroman feminino na análise do corpus.

Palavras-chave: Elementos góticos; Contos; Formação Feminia; Lygia Fagundes Telles.

ABSTRACT: The article presents a reading of the Gothic elements of the tale O Espartilho by Lygia Fagundes Telles and the meaning of these elements in the apprenticeship of the protagonist. The elements will be analyzed only in order of importance in the narrative. Within the article we still consider the category "feminine apprenticeship narrative" that leads to the approach of several elements of the female Bildungsroman in the analysis of the corpus.

Keywords: Gothic elements; Tales; Female apprenticeship novel; Lygia Fagundes Telles.

\section{INTRODUÇÃO}

O Bildungsroman feminino é motivo de muita polêmica entre diversos teóricos da literatura. Muitas delas giram em torno da própria existência do gênero. Estudos mais recentes

\footnotetext{
${ }^{1}$ Mestre em Literatura pela Universidade de Brasília (UnB). Professora Assistente da Universidade Estadual de Londrina (UEL). E-mail: adrianamattosorodrigues@ gmail.com
} 
consideram que os Bildungsromane femininos começaram a aparecer no século XIX, pois antes desse período a Bildung ${ }^{2}$ feminina era apenas uma projeção. Os romances anteriores, também chamados de Bildungsromane domésticos, são criticados na sua inclusão como Bildungsromane por não haver neles o processo ou a conclusão da formação feminina. Uma das teóricas que se debruçaram sobre o gênero, Esther Labovitz (apud SCHWANTES), alega que "neles não há Bildung, pois, mesmo quando a heroína tenta atingir o autoconhecimento, o romance termina em derrota" (SCHWANTES, 1998, p. 34). Desse modo o romance de formação feminino só passaria a existir no momento em que se acena à mulher a possibilidade de se inserir socialmente sem ter que se casar.

O romance de formação feminino também pode apresentar características psicológicas herdadas dos romances góticos. A incorporação desses elementos por tais narrativas é uma forma de trazer para dentro do texto, no nível simbólico (psicanalítico), características femininas que fogem à linguagem e à lógica masculina (SCHWANTES, 1998, p. 7). Além desses, o conto O Espatilho (1999), de Lygia Fagundes Telles, (doravante LFT), possui outros elementos considerados definidores do gênero por Cristina Ferreira Pinto, Annis Pratt e outras estudiosas. Esses elementos são: a infância da personagem, conflito de gerações, autoeducação, alienação e problemas amorosos (FERREIRA PINTO, 1990, p. 14).

No que tange $O$ Espartilho, como conto e devido a sua curta duração é usada uma técnica para narrar os acontecimentos apenas no tempo em que eles provocam alguma mudança na personagem. Esse recurso possibilita ao leitor alcançar todo o processo de formação desta. Com avanços no tempo mostrando a causa de algum fato ocorrido na narrativa antes mesmo de narrar o fato com clareza conseguimos perceber a importância dele para o aprendizado da personagem. O tempo na narrativa, apesar de se tratar de um texto com apenas 35 páginas, é assim estendido, conseguindo expressar o amadurecimento da protagonista através da comparação feita por ela própria entre suas impressões infantis e as adultas, se encaixando em uma das características descritas por Bakhtin como pertencentes ao romance de formação, descrita na citação abaixo:

"O tempo se interioriza no homem, passa a integrar a sua própria imagem, modificando substancialmente o

$2 \mathrm{O}$ termo Bildung que deu origem à palavra Bildungsroman, é um termo do médio alto alemão que indicava além de foma como também formação e desenvolvimento de características pessoais do intelecto humano (MAAS, 2000, p. 26). 
significado de todos os momentos do seu destino e da sua vida" (BAKHTIN, 2003, p. 220).

A narrativa traz como tema principal o conflito de gerações entre avó (sem nome durante toda a narrativa) e neta (Ana Luísa). Além disso, o conto aborda toda uma problemática feminina em relação à adaptação às normas vigentes (representadas pelo espartilho). Com uma narradora homodiegética, o conto segue as experiências, descobertas e reflexões de Ana Luísa, que a levam ao amadurecimento. Tais comparações só são possíveis pela reflexão da própria personagem, após um momento epifânico ${ }^{3}$. Em narrativas psicológicas (como a presente), não raro as epifanias são as responsáveis pela conciliação entre consciente e subconsciente. No caso do conto, elas servem para que o processo de formação apareça de forma completa dentro de uma narrativa curta.

Durante a narrativa a protagonista vai descobrindo as diferenças das regras sociais proclamadas e as que de fato são praticadas. O conhecimento dessa mecânica paradoxal, a meu ver, é a atual Bildung feminina. Segundo Annis Pratt (apud SCHWANTES):

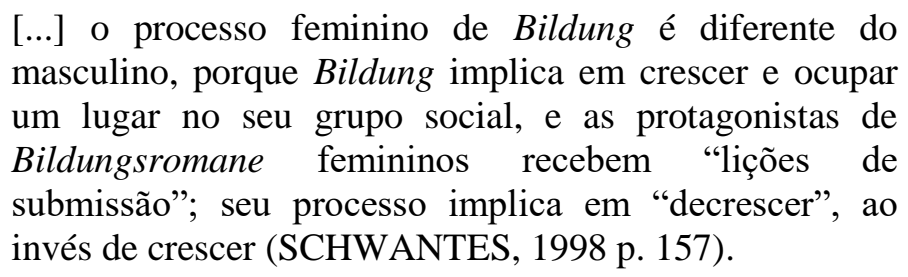

Apesar da nomenclatura Bildungsroman se referir a romances há no conto elementos suficientes para que ele seja analisado como um conto de formação, sobretudo se considerarmos a época em que a narrativa se situa. No período em que foi cunhado o termo a formação da mulher não passava pelas mesmas etapas que a masculina e tão pouco poderia ter os mesmos resultados. Entretanto, além de possuir os elementos considerados característicos pela crítica atual, o conto $O$ Espartilho de LFT (publicado em 1978) é ambientado no período que antecede à II Guerra (século XX), podendo então ser considerado uma narrativa de formação feminina. Nele a neta Ana Luísa é meio judia, por parte de mãe, órfã que é criada pela avó paterna.

3 As epifanias são os momentos onde algo que a personagem tinha conhecimento prévio, mas que estava adormecido, esse algo lhe é revelado. Algo que chega ao seu alcance de forma tão clara que não é mais possível não encarar a existência desse algo. 


\section{A rainha branca, o duplo, e Margarida, o outro (duplo)}

No conto avó e neta são repletas de semelhanças. Pode-se dizer que há entre elas uma duplicação, pois a primeira consegue, por meio da autorreflexão, se ver nos defeitos da outra uma imagem inversa refletida. Ao ler o conto percebemos que a metade podre de Ana Luísa vem da avó. Todos os seus defeitos são os mesmos desta - soberba e avareza. Nos jogos de xadrez entre as duas fica clara a posição de cada uma como um lado da mesma moeda. A avó é sempre a rainha branca e Ana Luísa, a resignada rainha preta. Essa comparação ressalta também a posição nazista da avó e a relação dessa com a origem judia da neta.

\footnotetext{
Fui buscar o tabuleiro e coloquei as pedras, as pretas eram sempre minhas. Não tinha a menor dúvida de que ia jogar mal. Viver mal. Fui perdendo as peças todas, uma por uma. Minha avó ficou impaciente: Por que não avança esse cavalo? Aprenda a lutar menina, vamos, reaja! A rainha branca atravessou o tabuleiro e encurralou o meu rei. Não tive por onde escapar (LFT, 1999, p. 44).
}

A partida de xadrez funciona como uma metáfora para o poder controlador da rainha branca. Ela mexe as peças do tabuleiro ao seu bel prazer, influenciando no destino das personagens como se elas fossem peças no seu tabuleiro. Quando a avó encurrala o rei negro de Ana Luísa e dá o xeque-mate, outra passagem do texto pode ser desvendada nessa leitura. A avó rainha consegue tomar o poder da neta ganhando autoridade suficiente para afastar Rodrigo (o amante libertador da sexualidade da neta) ao suborná-lo com o dinheiro para sua viagem à Irlanda. Assim ela interdita o amante da neta e mostra ainda a força de seu poder econômico.

Outra semelhança descrita no texto é revelada quando Ana Luísa é obrigada a comparar as duas imagens diferentes que tem da família. Ela questiona então tudo que aprendera com a avó: "Aprendi com a minha avó a classificar as pessoas em dois grupos nítidos, as pessoas boas e as pessoas más" (LFT, 1999, p. 32).

O maniqueísmo é outra característica da avó de Ana Luísa que remete aos romances góticos. Ele evidencia mais uma semelhança característica do duplo existente entre as duas. Já que Ana Luísa foi criada pela avó e acreditava ter os mesmos defeitos dela, era também maniqueísta. Sendo a avó boa ela deveria então ser má. Daí a confusão e o medo da menina ao 
descobrir que as pessoas que deveriam ser boas e perfeitas possuíam outras nuances e não poderiam mais ser classificadas dessa forma. Outra característica em comum das duas personagens é o preconceito. No episódio do fim do namoro de Margarida com um rapaz importante, as falas de ambas são muito parecidas. Ana Luísa e a avó se veem numa posição de superioridade tanto econômica quanto social frente à criada.

Avó:

Margarida, pode ir lavando a cara que você não vai ver esse moço. Ele é branco, querida. De família importante. Eu seria criminosa se consentisse nesse namoro (LFT, 1999, p. 36).

\section{Ana Luísa:}

Não fique assim, querida, pedi. Minha avó tem razão, agora você vai arrumar um outro namorado que seja assim da sua cor, presta atenção, da sua cor (LFT, 1999, p. 36).

Mais tarde, ao relembrar como agia nas tardes de caridade, de acordo com o que a avó lhe ensinara, um comportamento falso e bajulador visto como "encantador" pelas senhoras, Ana Luísa acaba revelando ao leitor mais uma semelhança entre ela e sua avó - o medo:

Eu precisava ser encantadora. Já era o medo mas esse medo me estimulava a amar o próximo, ou melhor, a fazer com que o próximo acreditasse nesse amor. Recebia em troca um juízo favorável e era nesse juízo que me sustentava. Estava aí a resposta à pergunta de Margarida, o que eu ganhava com isso? (LFT, 1999, p. 43).

Esse medo que nela é aparente, fica escondido na avó, no fundo. O medo de ser diferente, de fugir às normas, não ser normal. É esse medo que faz com que a avó invente outras histórias para os retratos do álbum. A consciência dessas semelhanças pode ser lida como o entendimento por Ana Luísa da condição feminina. A protagonista descobre ao final a fraqueza e humanidade por trás daquele espartilho. Uma amarra tão forte que deixa o amor da avó escondido lá no fundo, muito fundo.

Além disso, aparece entre elas outra duplicidade quanto ao sobrenome da família. O orgulho da avó é ser uma Rodrigues. A mancha de Ana Luísa é ser também Ferensen (judia). 
Mas ao analisar a história da família Rodrigues no Brasil encontra-se uma surpresa. Das várias famílias Rodrigues no país, posto que esse sobrenome na sua origem significava apenas "filho de Rodrigo", as mais nobres e ricas que aqui ficaram eram justamente as de origem judaica, sendo de portugueses e espanhóis cristãos-novos. Isso faz com que no mínimo a avó tenha se casado com um judeu.

Outro par presente no conto é representado por Ana Luísa é Margarida. Ambas são parentes e dependentes da avó, mas Margarida é vista apenas como uma criada. As oposições e semelhanças entre elas são facilmente enumeradas. Ambas são mestiças, uma mulata e a outra meio judia:

\footnotetext{
Metade do sangue de Margarida era negro mas a metade do meu. [...] Teria agora que fazer como Margarida? Apagar as pegadas da minha mãe - também eu? [...] Nela a metade maldita era evidente. E em mim? [...] Eu tinha uma metade ruim, aquela que intrigava, bajulava. Traía. Nessa metade estava o medo. Seria esse medo que me fazia assim dissimulada? (LFT, 1999, p. 39)
}

Ana Luísa aprendeu a desprezar a criada devido a sua condição racial, ao seu nascimento pobre. Ao descobrir, além do parentesco com ela, a sua própria metade podre, também de nascimento, a protagonista se arrepende de seu comportamento e começa a se ver semelhante a ela (afinal, eram também parentes).

Ambas têm mães interditadas como modelos e coincidentemente, mortas. Elas sofrem com a interferência da avó em suas vidas amorosas. As maiores oposições entre as duas residem no fato de Margarida ser mulata e em razão disso também, bastarda. Talvez se a ascendência judia de Ana Luísa fosse uma característica marcante ela também fosse abertamente desprezada pela avó.

\section{A sacola e o espartilho}

O poder exercido pela avó é representado pela sacola de seda que contém desde agulhas e linhas, instrumentos que tecem a história, chaves que abrem e fecham as portas do casarão e o dinheiro, que representa o poder econômico. A sacola é seu falo postiço. Como não é um homem, ela exerce seu poder através do dinheiro que possuí, representado pela sacola. Mas ela 
não pode usar a sacola naturalmente. $\mathrm{O}$ espartilho está ali para lembrar-lhe que o poder não emana de si. O uso do espartilho é a condição sine qua non para usar a sacola - a adequação às normas.

O espartilho é uma peça íntima que mudou ao longo dos anos, mas no início seu principal objetivo era limitar os movimentos femininos. Alguns chegavam a ser tão limitadores que dificultavam até mesmo a respiração. O corpo da avó está tão fortemente preso que ela se sente segura então para amarrar as vontades e desejos de suas protegidas para que não fujam desse molde. Ele também pode ser entendido como a punição para quem usa a sacola, como um artefato encantado que exerce uma influência mental e física naquele que o porta. O poder, que não é naturalmente feminino, traz consequências para as mulheres que o exercem. $\mathrm{O}$ uso desse artefato possui um encantamento tão forte que ao tocar a mão da avó, no final do conto, Ana Luísa percebe que ela tem as mãos amareladas e manchadas iguais aos retratos do álbum. Ele também funciona como uma barreira, impedindo que avó e neta se relacionem com carinho ou se unam contra essa dinâmica que no fundo é nociva às duas: "Eu sabia que no fundo ela me amava, mas porque esse fundo era tão fundo assim?” (LFT, 1999, p. 63)

Ana Luísa vai aos poucos relacionando seus conhecimentos e suas descobertas para se empoderar. Após descobrir seu sangue judeu ela começa a questionar os conhecimentos fornecidos pela avó e passa a fugir desse molde. Simulando uma conversa com esta, em meio as suas lembranças, ela compara os atuais acontecimentos de sua vida, que fogem ao padrão espartilhado, com os moldes ensinados por sua avó:

[Raríssimas mulheres sentem prazer, filha. [...] Então a mulher precisa fingir um pouco, o que não tem essa importância que parece. Temos que cumprir nossas tarefas e o resto é supérfluo. Se houver prazer, melhor, mas e se não houver? Ora, ninguém vai morrer por isso.

Ninguém? Pensei nas mulheres do álbum. Tirariam as jóias. Os vestidos. Hora de tirar o espartilho, tão duras as barbatanas. Os cordões fortemente entrelaçados. Se deitariam obedientes, tremendo sob os lençóis. "Ninguém vai morrer por isso." Mas há muito elas estavam mortas] (LFT, 1999, p. 52, grifos meus).

A morte narrada pela protagonista não é apenas física, mas simbólica. As mulheres espartilhadas do álbum morreram em decorrência do uso do espartilho. A prisão de seus desejos 
impossíveis de se conciliarem com a sociedade apagou suas verdades e as espartilhou no grande álbum. Ana Luísa a princípio não percebe os efeitos do uso do espartilho, mas a epifania proporcionada por Margarida a faz preencher as lacunas por trás das palavras fugidias e dos olhares laterais de sua avó. A citação a seguir deixa clara a imagem que a protagonista fazia dos retratos antes da revelação: "Não, não podia haver nenhuma sujeira de ambição e sexo nos corações espartilhados dos mortos do álbum” (LFT, 1999, p. 32).

Assim que compreende essa dinâmica, Ana Luísa passa a negar esse molde do feminino frio e impiedoso representado por sua avó. Ao fazer isso ela se aproxima daquilo que a avó mais parece desprezar - as pessoas desinteressantes e medrosas. Atitude que a avó rebate tentando casar a neta, pois esse era o destino das jovens obscuras. E ao comentar a crescente "deformação" da neta ela a compara com a mãe, dizendo que estão cada vez mais parecidas. Curiosamente, a avó jamais mencionou alguma característica da mãe de Ana Luísa, somente a timidez. A natureza judia de Ana Luísa só passa a ser conhecida através de Margarida e em face a essa marcante constatação, a neta judia da avó nazista vai deixando de se duplicar na avó.

\section{O álbum encantado de retratos}

A primeira lembrança de Ana Luísa é de se sentar no sofá da sala, junto da avó que tricota, e poder folhear o grande álbum de couro verde e cantoneiras de prata, quando esta permite. Pedaços da história da família já começam a aparecer nesse primeiro momento da narrativa: as "coisas” que um dia a pequena Ana Luísa irá compreender. A avó vai tricotando e tecendo as histórias desses familiares ao mesmo tempo em que sua neta vira as páginas. Ana Luísa vai então vendo o tecido de histórias feito com as agulhas poderosas da avó.

Esse objeto não é um simples álbum de retratos. Ele aprisiona vidas e histórias muito diferentes daquelas escolhidas pela avó rainha. Os verdadeiros retratos dos familiares aprisionados não correspondem às belas imagens virtuosas que a avó fazia questão de mostrar. Todas as virtudes ressaltadas por essa são na verdade contrárias a tudo aquilo que ela pregava.

Os retratos têm um papel importante no conto já que propiciam à Ana Luísa o questionamento das verdades proclamadas pela avó. Ao tentar encontrar o motivo para tal sorriso ou certa pose a narradora passa também a procurar o que revela a foto, o real por trás da aparência. Quando acontece a epifania do conto, o momento no qual Margarida revela à prima 
o que de fato aconteceu com seus familiares, Ana Luísa passa a duvidar do que avó fala e também de si mesma. As reticencias e os silêncios da avó passam a ter outro significado.

[...] mas que família era essa que ela me apresentava? Gente insegura. Sofrida. Que eu teria amado muito mais do que as belas imagens descritas pela minha avó. Mas tive medo de descobrir o medo alheio (LFT, 1999, p. 32).

A segurança da personagem vinha justamente da certeza de ser tal um retrato daquele álbum. Ao descobrir sua ascendência judia e o motivo da ausência de retratos de sua mãe no álbum de família, Ana Luísa parece se reconhecer com uma metade defeituosa. Tal como a prima Margarida, que é mestiça, Ana Luísa é uma meio-judia na casa de uma avó nazista. Após esse acontecimento Ana Luísa passa a fugir da avó.

A personagem passa então a ter duas escolhas: entrar no espartilho social, tal como a avó, ou casar-se para fugir. Nesse caso ela teria então que se submeter ao marido (um indicativo da chamada deformação feminina, a impossibilidade de acordo). Devido a sua origem abastada ela tem mais oportunidades do que a maioria das mulheres naquela época. A ela é permitido estudar, ir ao cinema e ter uma certa liberdade de ir e vir e fazer o que lhe interessasse. Mesmo assim, a opção que a deixaria livre ainda não era comum nem aceitável. Ela não poderia simplesmente sair de casa e ir morar sozinha, sair do álbum.

\section{CONSIDERAÇÕES FINAIS}

Ao final do conto temos uma conversa conciliatória e reveladora entre avó e neta. Motivada pela partida de Rodrigo, essa conversa mistura a imaginação de Ana Luísa com fragmentos da conversa real, da qual nós inferimos que a avó também se orienta pelo que a neta estaria pensando. A protagonista percebe o valor dessa experiência amorosa como se ela fosse prepará-la para outra, mais completa. Ela descobriu que era enfim capaz de amar e ser amada.

\footnotetext{
Alimentei ilusões, avó. Mas não estava ainda pronta para o amor, não sei como é com os outros mas no meu caso tinha que me preparar, lá sei! amadurecer. Agora já sei, pelo menos acho que sei. O que perdi em ilusão, ganhei em segurança (LFT,1999, p. 61).
} 
Nesse momento a formação parece estar se completando. Ana Luísa entende as motivações da avó ao tocar no espartilho e ao perguntar se ela precisaria de ajuda para tirá-lo e ouve em resposta da avó que se sente melhor com ele. Ela acaba então por perdoar a avó por tudo o que fez. $\mathrm{O}$ espartilho revela à neta que existe uma humanidade por debaixo daquela dureza toda. Ela reconhece ainda ser esta humanidade muito funda devido ao uso prolongado do espartilho. Mas reconhece também que a avó não tem mais salvação, pois está se tornando um retrato do álbum. Isso significa que sua história e seus verdadeiros sentimentos ficarão desconhecidos para a neta e para todos que vierem depois dela.

Assim como muitas das narrativas de formação feminina, $O$ Espartilho não traz solução para dilema nem tão pouco uma conciliação plena. Esses elementos não aparecem dentro da narrativa. Não fica claro ao leitor se ela sairá realmente da casa da avó ou se tornará como ela um retrato preso no álbum. O último parágrafo do texto revela pouco: "Antes de sair, abri a janela. A Via-Láctea palpitava de estrelas. Respirei o hálito da noite: logo iríamos amanhecer” (LFT, 1999, p. 64).

O final é apenas sugerido e a solução é algo que está projetado para além do conto, depois da última página. Resta então somente imaginar um desfecho. Quem iria de fato “amanhecer”? Ana Luísa e as estrelas, indicando que a protagonista se libertou da avó e adquiriu sua independência, ou ela e a avó, mostrando que no fundo ela se resignou e entrou no espartilho social apesar de tudo? Alegoricamente, o amanhecer é o início da vida. Apenas a protagonista tem vida a ser iniciada, a avó está no ocaso. Mas essa alegoria não é suficiente para dar ao leitor uma certeza sobre o destino de Ana Luísa.

Devido à incompletude do processo de formação pode-se apenas inferir da protagonista que ela realmente fugirá dessa dinâmica, pois adquiriu a consciência da condição feminina. Ela viu os efeitos do espartilho e quebrou o encanto do álbum de retratos. A falta de uma conclusão parece servir para convidar o leitor a também procurar o misterioso destino que é reservado àqueles que se soltam das amarras - o depois do "foram felizes para sempre".

\section{REFERÊNCIAS}

BAKHTIN, Mikhail. Estética da Criação Verbal. São Paulo: Matins Fontes, 2003. 
MAAS, Wilma Patrícia Dinardo. O cânone Mínimo: o Bildungsroman na história da literatura. São Paulo: Editora UNESP, 2000.

PINTO, Cristina Ferreira. O Bildungsroman feminino: quatro exemplos brasileiros. São Paulo: Perspectiva, 1990.

SCHWANTES, Cíntia. Interferindo no cânone: a questão do Bildungsroman feminino com elementos góticos. Tese de doutorado. UFRGS, 1998.

TELLES, Lygia Fagundes. O Espartilho. In: A Estrutura da Bolha de Sabão. Rio de Janeiro: Rocco, 1999. 